\title{
Positron Emission Tomography
}

National Cancer Institute

\section{Source}

National Cancer Institute. Positron Emission Tomography. NCI Thesaurus. Code

C17007.

A technique for measuring the gamma radiation produced by collisions of electrons and positrons (anti-electrons) within living tissue. In positron emission tomography (PET), a subject is given a dose of a positron-emitting radionuclide attached to a metabolically active substance (for example, 2-fluoro-2-deoxy-D-glucose (FDG), which is similar to a naturally occurring sugar, glucose, with the addition of a radioactive fluorine atom). When living tissue containing the positron emitter is bombarded by electrons, gamma radiation produced by collisions of electrons and positrons is detected by a scanner, revealing in fine detail the tissue location of the metabolically-active substance administered. 